\title{
El movimiento laboral frente a la privatización
}

Si bien durante los primeros meses del año la dinámica del movimiento gremial-sindical se vio condicionada profundamente por la coyuntura electoral; tras el evento, y definido el nuevo espectro político, las consecuencias que supone la implementación del programa de ajuste estructural, impulsado por el gobierno se han venido constituyendo en la preocupación más urgente del movimiento popular organizado.

Como era de esperar, la ejecución de este plan de ajuste y, en general, la orientación neoliberal que envuelve al quehacer del gobiemo de ARENA, han significado la apertura de nuevos puntos de conflicto entre el movimiento de los trabajadores y el proyecto político estatal. Dos de ellos, probablemente los fundamentales en el caso salvadoreño, son los referidos a los proyectos de privatización —o eliminación- de las instituciones de servicios públicos y a los de parcelación individual de las tierras afectadas por la reforma agraria.

Ciertamente, se trata de dos problemas que ya desde inicios del año han venido generando algún tipo de respuesta del movimiento popular. Sin embargo, es a lo largo del segundo semestre que se fueron definiendo más precisamente como los escenarios fundamentales de las luchas laborales, al menos en términos coyunturales.

De esta suerte, los meses de mayo y agosto se han perfilado como los períodos de mayor efervescencia laboral en protesta por estos proyectos. Así, en lo que al escenario gremial-sindical se refiere, mayo estuvo en lo fundamental dominado por las movilizaciones en torno al problema de la parcelación de las árèas reformadas y a las tomas de tierras, cuestión esta última que se extendió durante los meses de junio y julio, y a la que el gobierno respondió con desalojos violentos de los campesinos ocupantes, hasta que se llegó a algunos acuerdos con las organizaciones de los trabajadores agrícolas que lograron paliar medianamente el problema (ECA, 1991, 510; Proceso, 473, $475,477,478,480$ ).

Por otro lado, en lo que toca al segundo eje de los conflictos generados por la aplicación de las medidas de ajuste, sus síntomas se comenzaron a expresar de forma concreta desde los meses de abril y mayo. Ya para esos meses, la problemática de la privatización de las empresas públicas ocasionó una serie de acciones sindicales que fueron una muestra de su considerable potencialidad como centro de conflictos socio-laborales (Proceso, 473, 474).

Al igual que en el caso de las tomas de tierras y de las protestas por la parcelación de la reforma agraria, junio y julio fueron escenarios de manifestaciones contra los proyectos privatizadores. Sin embargo, las acciones se caracterizaron por ser actividades relativamente aisladas y particulares. Ha sido hasta el mes de agosto que las centrales sindicales y gremiales más importantes han confluido en acciones coordinadas contra los proyectos de privatización y eliminación de las empresas públicas, con el objetivo de presionar al gobierno a dialogar y concertar con los trabajadores.

Por sus implicaciones y alcances en términos no sólo de desempleo, sino también de las trans- 
formaciones mismas del Estado y sus funciones, los procesos privatizadores se han constituido en una preocupación no exclusiva de las organizaciones laborales. Asi, en los últimos días de julio, en el marco de una ya acentuada actividad de los trabajadores estatales y municipales aglutinados en UNASTEMA, la asamblea legislativa se pronunció por crear una comisión para evaluar los procesos de privatización.

Pero, como se ha venido apuntando, los programas antiestatistas generados por el proyecto gubernamental, y justificados bajo los argumentos de inoperancia institucional, ineficiencia económica y corrupción administrativa de las entidades de servicios públicos, han ido más allá de la clásica medida de privatización de las instituciones estatales, Durante los meses de julio y agosto, la tendencia ha sefialado una orientación en principio más grave: los programas de reducción del aparato gubernamental incluirían como punto fundamental la eliminación definitiva de las entidades públicas, sea por decisión ejecutiva o legislativa. De esta suerte, tres casos que se han vuelto paradigmáticos son los beneficios del INCAFE que aún funcionaban, el Instituto de Vivienda Urbana (IVU) y, finalmente, el Instituto Regulador de Abastecimientos (IRA), los cuales han sido ya aniquilados definitivamente y sus trabajadores indemnizados.

Es en este marco que, durante el mes de agosto, el debate y las protestas laborales y de la oposición política en torno a la cuestión de la privatización se han venido incrementando considerablemente.

El motivo detonante de la efervescencia laboral y de los encontrados debates que sobre el punto han sostenido diversos sectores políticos, ha sido la decisión del gobierno central de cerrar definitivamente el Instituto Regulador de Abastecimientos (IRA). Medida tomada al iniciarse el mes de agosto, pese al acuerdo legislativo de estudiar el caso antes de tomar alguna decisión y a las gestiones que desde mediados de mayo venían realizando los trabajadores al proponer un "Proyecto de reactivación y mejoramiento de los servicios del IRA", el cual consideraban una alternativa viable a la privatización. Además, los trabajadores aseguraron que los planes gubernamentales afectarian a unos 1,300 trabajadores y que los mayores problemas de la institución son producto de la corrupción de los funcionarios. Posteriormente, a mediados de julio, el sindicato de trabajadores de esa entidad (ASTIRA), presentó a la asamblea legislativa un proyecto de reforma orgánica a la ley de creación del IRA, para fortalecer la institución.

Pese a todo esto, el 1 de agosto fue sorpresivamente anunciada la clausura del IRA y el desembolso correspondiente a las indemnizaciones de los trabajadores. Sin embargo, aún cuando el cierre de esta institución, al igual que el caso del Instituto de Vivienda Urbana (IVU), parecen, de hecho, procesos consumados, las discusiones en torno a los mismos e incluso la demanda de su reapertura se mantienen. $Y$ ello al menos por dos razones.

En primer lugar, por el desempleo que este tipo de medidas implica para la población trabajadora. Según cifras proporcionadas por dirigentes sindicales, 18,134 empleados públicos han sido despedidos en los últimos seis meses, lo cual en sí mismo es fuente de graves tensiones sociales. Pero, en segundo lugar, porque tal situación ha significado no la privatización o sustitución de servicios prestados por el Estado, sino la desaparición de la función reguladora del abastecimiento de granos básicos, y de la de subsidio y financiamiento para la construcción de viviendas.

Es frente a estas medidas gubernamentales que las principales centrales laborales, y especialmente las organizaciones de trabajadores del sector público, han respondido con una serie de acciones reivindicativas y de protesta que incluyen marchas, concentraciones y paros laborales. En agosto, las de mayor alcance habrian sido el paro general del sector público, convocado para el pasado 19 de agosto, y el realizado el 29 del mismo mes.

El paro de ocho horas, realizado el 19 de agosto, según fuentes sindicales, fue efectivo en unas veinte instituciones estatales y en unas 100 de las 262 alcaldias del país. Dirigentes de la UNTS, UNOC, AGEPYM, CTS, de la intergremial y UNASTEMA —organizaciones que convocaron y coordinaron el paro- mencionaron, entre las ins- 
tituciones afectadas por la acción de protesta, a los ministerios de Hacienda, Obras Públicas, Educación, Salud y Agricultura, así como a la Lotería Nacional de Beneficencia, parte del magisterio que labora en instituciones públicas y privadas. ANTEL, ANDA, una parte del ISSS, INPEP, FSV, ISTU, CEPA-Acajutla, Correos Nacionales, CEL y la Universidad de El Salvador. De acuerdo a los datos de los sindicalistas, en el paro habrian participado entre 60 y 65 mil trabajadores estatales. La actividad estuvo acompanada de diversas expresiones de protesta, entre las que inclusive se verificaron tomas de tramos de calles en la capital.

Al objetivo fundamental de la movilización, que era, ciertamente, la protesta por la privatización y, o cierre de algunas instituciones estatales y la presión al gobiemo para concertar con los trabajadores, se sumaron otras demandas igualmente fundamentales, vinculadas con las condiciones laborales y salariales de los trabajadores, entre ellas, la exigencia de 500 colones de aumento salarial para todos los empleados públicos y la solución a las demandas particulares de cada organización de trabajadores del sector público.

El solo llamado al paro formulado por las centrales laborales provocó la aparición del presidente Cristiani en cadena nacional, acusando a los sindicalistas responsables de la movilización de ser "miembros de organizaciones que han venido realizando acciones dirigidas a manipular a trabajadores de la administración pública, para llevar a cabo actos contra la Constitución, las leyes y sobre todo contra el pueblo salvadoreño", en el marco de una maniobra estratégica del FMLN; por lo que hizo un llamado a "todos los empleados públicos para que desatiendan esas incitaciones a una huelga política y se presenten a cumplir con sus obligaciones". Adicionalmente, el presidente recordó a los trabajadores que el artículo 221 de la Constitución prohibe tales acciones en el sector público.
Concluida la acción reivindicativa y de protesta, tanto el gobiemo central como las patronales respectivas, negaron la efectividad del paro en la magnitud seffalada por los trabajadores y han aseveraron que en lo fundamental se laboró con regularidad. El viceministro de la presidencia añadió que el paro fue un "rotundo fracaso", y advirtió que los líderes sindicales que incitaron a la huelga y los trabajadores que la apoyaron sufrirían los descuentos correspondientes por el tiempo no laborado.

La movilización tuvo una característica novedosa y particular al recibir el apoyo de los diputados de los partidos Convergencia Democrática, PDC y UDN, quienes no asistieron a la asamblea legislativa ese día. En este sentido, se convirtieron

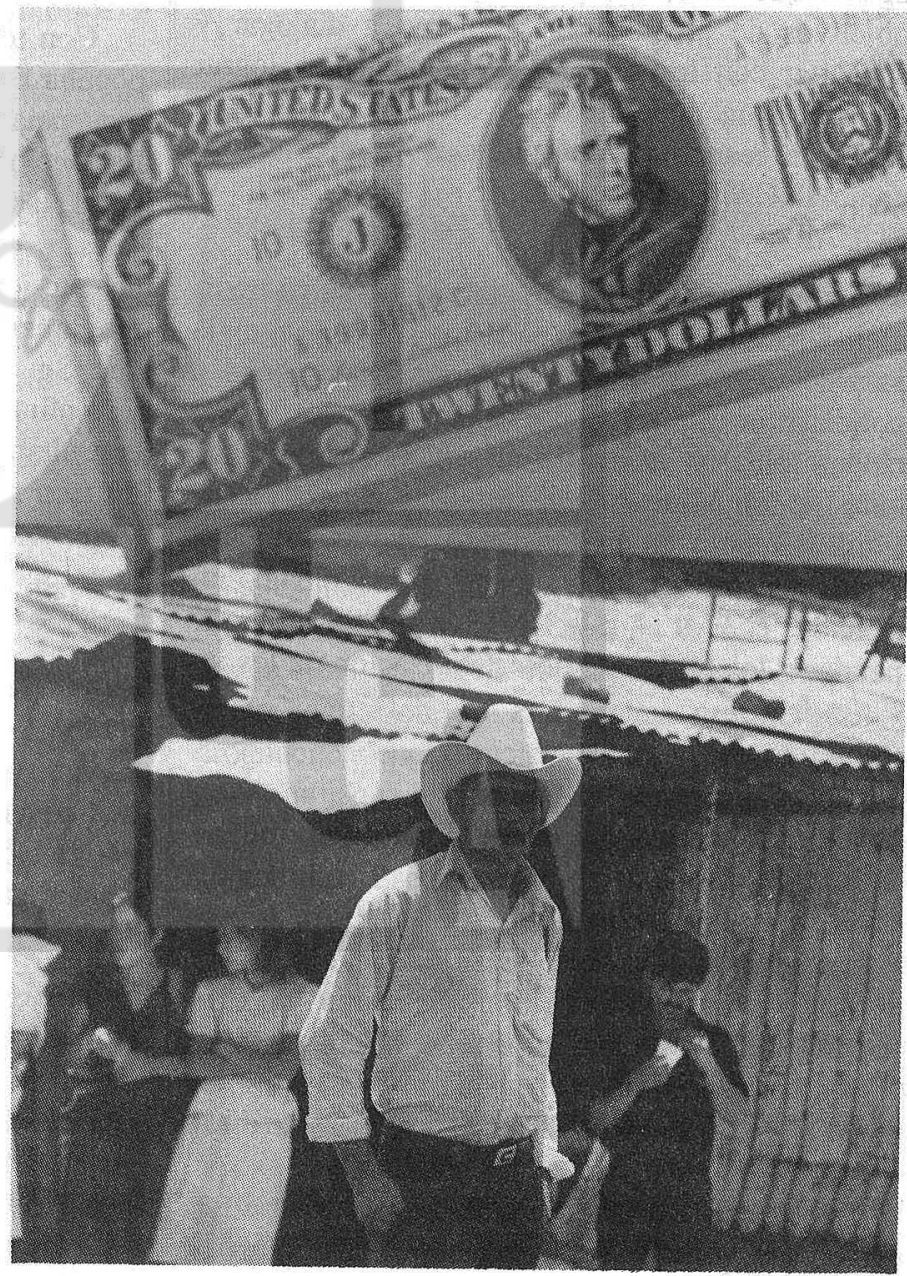


también en blanco de las acusaciones gubernamentales de colaborar con las planes desestabilizadores del FMLN. Ante esto, diputados de la Convergencia enfatizaron que la acción de los empleados estatales no debe leerse como un acto confrontativo, sino como el uso de un derecho para defender el trabajo. En general, la posición de los diputados de las fracciones opositoras provocó fuertes críticas por parte de la dirigencia de ARENA. Entre otros, el alcalde Armando Calderón Sol declaró que ese apoyo califica a dichos diputados como "una oposición insurreccional, es una oposición que invita a la desobediencia civil y al incumplimiento de las leyes y de las normas salvadoreñas".

A esta acción siguió la movilización del 29 de agosto que tuvo, en lo fundamental, los mismos objetivos de presionar al gobierno a dialogar y consultar con los sectores populares, para lograr un programa alternativo de consenso, así como exigir la reapertura de entidades ya clausuradas como INCAFE, IRA, IVU, ISIC, CENTA, INAZUCAR.

La respuesta gubernamental repitió su ya tradicional acusación de ser partícipe de la estrategia insurgente a toda expresión de disensión social o política. En esta ocasión, sin embargo, las acusaciones tomaron un matiz más preocupante, dado que fue el Ministro de Defensa, general René Emilio Ponce, quién las lanzó. Particularmente, Ponce acusó, en base a supuestos documentos incautados al FMLN, a la UNTS y al CPDN de responder a los planes de desestabilización de los in- surgentes. Declaraciones que suscitaron una serie de protestas tanto de los sectores sindicales como de los organismos políticos, dadas las consecuencias que de ellas se podrian derivar sobre la seguridad personal de los dirigentes de esas organizaciones.

Por lo pronto, ante la cerrada actitud del gobierno y la atribución de motivos políticos a lo que son acciones reivindicativas legítimas de los trabajadores, las organizaciones sindicales han señalado que de no flexibilizarse, el gobierno "tendrá la responsabilidad sobre sus espaldas de cualquier acción que nos encaminemos a realizar de aquí en adelante al no atender a nuestras peticiones, pero queremos quedar claros de que no estamos cerrados a negociar en el momento oportuno que el presidente considere conveniente".

Con todo, los problemas a que el movimiento popular debe hacer frente no se agotan en las consecuencias derivadas de los planes privatizadores. Las acciones represivas contra la organización laboral, las precarias condiciones salariales y laborales, o el considerable incremento en las tarifas del servicio eléctrico han sido cuestiones a que el movimiento de los trabajadores ha debido responder. Sin embargo, los proyectos de privatización y, o eliminación de las empresas estatales que inconsultamente el gobiemo ha comenzado a ejecutar, son por hoy el reto inmediato más grave que se plantea al movimiento gremial y sindical.

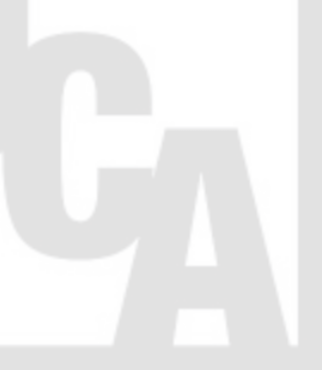

